\title{
Prophylaxis of postoperative deep vein thrombosis: selective use of low-dose heparin in high-risk patients
}

\author{
A J CRANDON, K R PEEL, J A ANDERSON, VALERIE THOMPSON, G P MCNICOL
}

\section{Summary and conclusions}

Administration of prophylactic low-dose subcutaneous heparin to prevent postoperative deep vein thrombosis is expensive, entails treating many patients unnecessarily, and causes some side effects. By using a predictive index a population of patients who are at particularly high risk of developing postoperative deep vein thrombosis may be identified preoperatively. Prophylaxis was given only to these patients, resulting in an incidence of deep vein thrombosis of $3.8 \%$ compared with $16.1 \%$ in previous studies in which no specific prophylaxis was given.

By limiting prophylaxis to the group of patients identified by the predictive index as being at high risk of developing postoperative deep vein thrombosis results may be obtained that are as good as those expected from treating the whole population. Thus many patients are saved from exposure to low-dose subcutaneous heparin.

\section{Introduction}

Deep vein thrombosis occurs after hysterectomy in $7-13^{\circ}$, of patients with benign disease and $25-45^{\circ}{ }_{0}$ of patients with malignant disease. ${ }^{1}$ Subcutaneous low-dose calcium heparin significantly reduces the incidence of postoperative deep vein thrombosis and pulmonary embolism ${ }^{2-4}$ but increases the incidence of bleeding complications ${ }^{235}$ and entails treating unnecessarily many patients who would not develop the condition even without heparin. It is therefore desirable to limit the prophylactic use of heparin to those at greatest risk of postoperative deep vein thrombosis.

Clayton $e t a l^{6}$ showed that accurate preoperative identification of high-risk patients was possible, and we recently confirmed the predictive power of their index prospectively in a new group of patients undergoing major gynaecological operations. ${ }^{7}$ The purpose of the present study was to use the index to select highrisk patients for the administration of prophylactic subcutaneous low-dose calcium heparin to try to prevent postoperative deep vein thrombosis and reduce the incidence of heparin-related complications when large populations are treated. The results are compared with those from our previous study, ${ }^{7}$ in which no prophylaxis was given.

\section{Methods and patients}

Euglobulin lysis time was measured using the method of Blix ${ }^{8}$ and serum concentrations of fibrin-related antigen by latex agglutination,

\footnotetext{
Department of Obstetrics and Gynaecology, Leeds Maternity Hospital, University of Leeds

A J CRANDON, MRCOG, MAUSTCOG, research registrar

The Hospital for Women, Leeds LS8 1NT

K R PEEL, FRCOG, FRCSED, consultant gynaecologist

School of Mathematics, University of Newcastle upon Tyne J A ANDERSON, MA, DPHIL, reader in statistics

VALERIE THOMPSON, BA, MSC, research associate

University of Leeds

G P MCNICOL, MD, PHD, professor of medicine
}

using Thrombo-Wellcotest. Preoperative height and weight were measured on admission with the patient wearing night attire and bare feet. The percentage overweight for height was then estimated. ${ }^{9} \mathrm{~A}$ predictive index was calculated for each patient using the formula of Clayton et al $^{6}$ :

$$
I=-11 \cdot 3+0 \cdot 009 a+0 \cdot 22 b+0 \cdot 085 c+0 \cdot 043 d+2 \cdot 19 e
$$

where $a=$ euglobulin lysis time $(\mathrm{min}), \mathrm{b}=$ concentration of fibrinrelated antigen $(\mathrm{mg} / \mathrm{l}), \mathrm{c}=$ age (years), $\mathrm{d}=$ percentage overweight for height, and $\mathrm{e}=$ presence or absence of varicose veins (scored as 1 or 0 respectively).

The predictive index was calculated for each of 105 patients, aged 40 years or over, abouit to undergo major gynaecological operations by the abdominal or vaginal route. Table I shows the indications for surgery in this trial and our previous study. ${ }^{7}$ All patients defined by

TABLE I-Distribution of disease among patients in this and our previous study. Figures are numbers $(\%)$ of patients

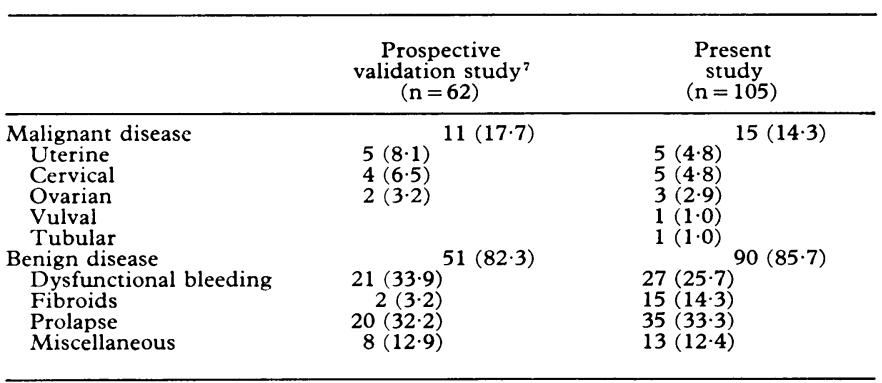

the index as being at high risk (those with scores equal to or greater than -2) received low-dose subcutaneous calcium heparin from single-dose preloaded disposable syringes, the dosage being 5000 IU two to four hours preoperatively and every eight hours postoperatively for seven days or until the patient was fully ambulant, whichever was the longer.

Diagnosis of deep vein thrombosis-All patients underwent isotope leg scanning, using ${ }^{125} \mathrm{I}$-fibrinogen. Deep vein thrombosis was diagnosed using the criteria of Kakkar. ${ }^{10}$ Postoperative scanning was performed on the first, third, and sixth days unless a high count was obtained, when daily scanning was started. All positive postoperative scans were confirmed by ascending phlebography.

\section{Results}

Based on the above criteria no patients had clinical or isotopic scan evidence of deep vein thrombosis before surgery.

Thirty-one of the 105 patients were identified preoperatively as being at high risk and given heparin. The remaining 74 patients received no specific prophylaxis. Four patients developed deep vein thrombosis postoperatively, one in the high-risk, heparin-treated group and the others in the low-risk group. Table II shows the median and interquartile ranges for the variables incorporated in the predictive index for these 105 patients, and figure 1 shows the distribution of the indices.

Statistical analysis-Conventionally in radiofibrinogen leg scanning deep vein thrombosis is diagnosed when there is a difference of more than $20 \%$ in the count between adjacent points on the same level or the same point on the contralateral limb. The results of the fibrinogen leg scanning were analysed in detail. Figure 2 shows the mean difference in radioactivity recorded externally at the midcalf level in the patients who were preoperatively identified as being at high or low risk. In both studies the preoperative difference tended to be greater in the high-risk patients. In our previous study, ${ }^{7}$ when no patients 
received specific prophylaxis, there was a progressive increase in this mean difference postoperatively, indicating the development of deep vein thrombosis. In the patients in the present trial, however, the effect of heparin in reducing this difference in the high-risk group is strikingly evident.

TABLE II-Distributions of the five variables incorporated in the predictive index subdivided for populations at high and low risk of developing deep vein thrombosis

\begin{tabular}{|c|c|c|c|c|}
\hline & \multicolumn{2}{|c|}{ High risk $(n=31)$} & \multicolumn{2}{|c|}{ Low risk $(n=74)$} \\
\hline & Median & $\begin{array}{c}\text { Interquartile } \\
\text { range }\end{array}$ & Median & $\begin{array}{c}\text { Interquartile } \\
\text { range }\end{array}$ \\
\hline $\begin{array}{l}\text { Euglobulin lysis time }(\mathrm{min}) \\
\text { Fibrin related antigen }(\mathrm{mg} / \mathrm{l}) \\
\text { Age (years) }\end{array}$ & $\begin{array}{r}185 \\
4 \\
65\end{array}$ & $\begin{array}{r}230 \\
6 \\
17\end{array}$ & $\begin{array}{r}100 \\
2 \\
45\end{array}$ & $\begin{array}{r}60 \\
3 \\
9\end{array}$ \\
\hline $\begin{array}{l}\text { Percentage overweight for } \\
\text { height }\end{array}$ & 12 & 16 & 3 & 17 \\
\hline $\begin{array}{l}\text { No }(\%) \text { of patients with } \\
\text { varicose veins }\end{array}$ & \multicolumn{2}{|c|}{$25(81)$} & \multicolumn{2}{|c|}{$18(24)$} \\
\hline
\end{tabular}

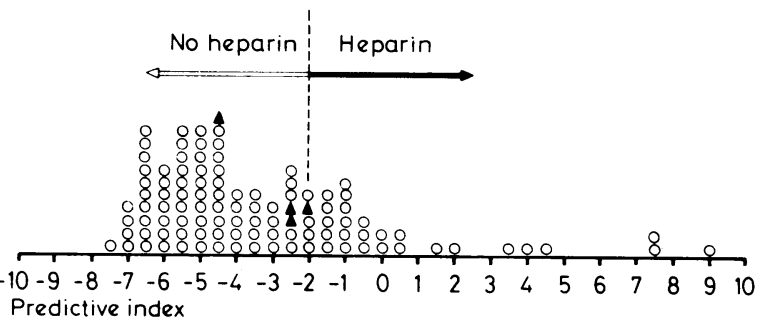

FIG 1-Distribution of preoperative predictive indices for the 105 patients studied, showing those who received low-dose subcutaneous calcium heparin.

$O=$ Patients who did not develop deep vein thrombosis.

$\boldsymbol{\Delta}=$ Patients who developed deep vein thrombosis.

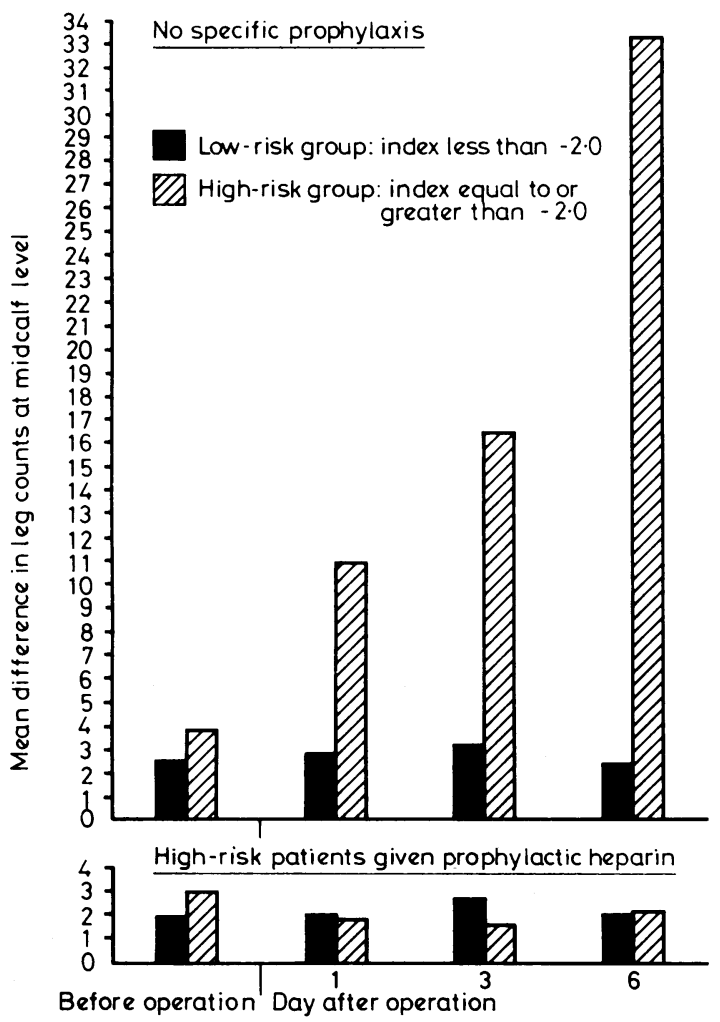

FIG 2-Mean difference in radioactivity recorded externally at midcalf level in patients in previous study (no specific prophylaxis) ${ }^{7}$ and those in the present trial (high-risk patients given prophylactic low-dose heparin). Results given according to whether patients identified preoperatively as being at high or low risk.

\section{Discussion}

In this study prophylactic low-dose heparin was given to an identified high-risk group, consisting of only $29.5 \%$ of patients having gynaecological operations. We thought that ethically such patients could not be randomly allocated to heparin versus a placebo. As the allocation of patients to the treated (heparin) and untreated groups was not random it was not appropriate to compare the incidence of deep vein thrombosis in these groups. Instead, we considered the whole group to determine whether the selective use of heparin reduced the overall incidence of deep vein thrombosis. For comparison we used the overall incidence of the condition in our previous studies ${ }^{6}$ ? -that is, 30 cases out of 186 patients $(16 \cdot 1 \%)$. The present study yielded an incidence of four cases in 105 patients $(3.8 \%)$. This difference is significant at the $1 \%$ level, using the $\chi^{2}$ test with Yates's correction. The results obtained are similar to those of Ballard et $a l,{ }^{11}$ who treated a whole gynaecological population with low-dose heparin with a resultant rate of deep vein thrombosis of $3.6 \%$. With our approach patients who were at low risk of developing postoperative deep vein thrombosis were saved the potential side effects of unnecessary treatment.

Although no patient developed deep vein thrombosis preoperatively, detailed analysis of the externally recorded radioactivity at the midcalf level (fig 2) showed that in both studies preoperative differences in counts tended to be greater in those patients identified as being at high risk. Venous thrombosis is said to be rare in healthy people, ${ }^{12}$ but Havig, ${ }^{13}$ in a detailed postmortem study, found small thrombi and pulmonary emboli in $20 \%$ of presumably healthy subjects who died almost instantaneously from accidents, and perhaps many of the patients who develop postoperative venous thrombosis already have small thrombotic foci preoperatively. Fibrinolysis in such circumstances would be protective, and postoperative fibrinolytic shutdown ${ }^{14}$ may permit extension of thrombosis. A relation between the extent of fibrinolytic shutdown and postoperative deep vein thrombosis has been shown. ${ }^{15} 16$

Selecting high-risk patients for preventive treatment appears to yield encouraging results. An incidence of $16.1 \%$ in patients in our previous studies contrasts with the $3.8 \%$ incidence in the patients in the present trial, in which heparin was given only to those at high risk. By using a predictive index it should be possible, in a study restricted to high-risk patients, to compare various currently used forms of prophylaxis on a random, double-blind basis with substantial economy of effort.

The cost of the two laboratory tests is small (about $£ 3.50$, including labour costs), but patients might need to be admitted to hospital a day or two earlier to undergo the tests or be seen at a special outpatient visit. Against this may be set the financial and other costs of unnecessary heparin treatment. Estimating euglobulin lysis time may be time consuming, and we have examined the possibility of using an index incorporating only the concentrations of fibrin-fibrinogen degradation products and the three clinical variables. Omitting the euglobulin lysis time results in an appreciable weakening of the predictive power, with, for example, in the present study some 30 extra patients being allocated to the high-risk group in order to achieve an adequate pick-up rate for patients at genuine risk.

Our predictive index was derived from and has been verified and tested on gynaecological patients. We do not know whether it would have equal predictive value in another group of patients -for example, patients having general operations. If general surgeons wish to use the same approach for selective administration of prophylactic heparin a new predictive index or a variant of the formula of Clayton $e t a l^{6}$ would have to be derived and its validity established.

We are grateful to Professor J S Scott for his interest and advice during the course of this work.

Financial support was received from the special trustees of the General Infirmary at Leeds.

We are grateful to Mrs B Griffin, Miss C Jackson, Mrs S Urquhart, Mrs G Levell, and Mrs $\mathrm{H}$ Hale for laboratory help. 


\section{References}

1 Walsh JJ, Bonnar JN, Wright FW. A study of pulmonary embolism and deep leg vein thrombosis after major gynaecological surgery using labelled fibrinogen, phlebography and lung scanning. Fournal of Obstetrics and Gynaecology of the British Commonwealth 1974 ;81 :311-6.

2 Gallus AS, Hirsh J, Tuttle RJ, et al. Small subcutaneous doses of heparin in prevention of venous thrombosis. $N$ Engl f Med 1973;288:545-51.

${ }^{3}$ International Multicentre Trial. Prevention of fatal post-operative pulmonary embolism by low doses of heparin. Lancet 1975 ;ii:45-51.

4 Lahnborg G, Bergstrom K, Friman L, Lagergren H. Effect of low dose heparin on incidence of post-operative pulmonary embolism detected by photoscanning. Lancet $1974 ; \mathrm{i}: 329-31$.

5 Belch JJF, Lowe GDO, Pollock JG, Forbes CD, Prentice CRH. Subcutaneous heparin in the prevention of venous thrombosis after elective aortic bifurcation graft surgery. Thromb Haemostas 1979;42:303.

${ }^{6}$ Clayton JK, Anderson JA, McNicol GP. Preoperative prediction of postoperative deep vein thrombosis. Br Med f 1976;ii:910-2.

7 Crandon AJ, Peel KR, Anderson JA, Thompson V, McNicol GP. Postoperative deep vein thrombosis: identifying high-risk patients. $\mathrm{Br} \mathrm{Med}$ f $1980 ; 281: 5278$.

${ }^{8}$ Blix S. Studies on the fibrinolytic system in the euglobulin fraction of human plasma. Scand $\mathcal{F}$ Clin Lab Invest 1961;13, suppl 58:3-19.
${ }^{9}$ Documenta Geigy. Scientific Tables. 7th ed. Macclesfield: Geigy Pharmaceuticals, 1970:712.

${ }^{10} \mathrm{Kakkar}$ W. The diagnosis of deep vein thrombosis using the ${ }^{125} \mathrm{I}$-fibrinogen test. Arch Surg 1972;104:152-9.

11 Ballard RM, Bradley-Watson PJ, Johnstone FD, et al. Low doses of subcutaneous heparin in the prevention of deep vein thrombosis after gynaecological surgery. Fournal of Obstetrics and Gynaecology of the British Commonwealth 1973;80:469-72.

12 Breckenridge RT, Ratnoff OD. Pulmonary embolism and unexpected death in supposedly normal persons. $N$ Engl f Med 1964 ;270:298-9.

${ }^{13}$ Havig O. Deep vein thrombosis and pulmonary embolism. Acta Chir Scand 1977;suppl 478.

${ }^{14}$ Pison J, Boyan P, Clifton EE. Fibrinolytic activity in patients during operation. FAMA 1965;191:1026-7.

15 Gordon-Smith IC, Hickman JA, Le Quesne LP. Postoperative fibrinolytic activity and deep vein thrombosis. Br $\mathcal{F}$ Surg 1974 ;61:213-8.

16 Knight MTN, Dawson R, Melrose DG. Fibrinolytic response to surgery: labile and stable patterns and their relevance to post-operative deep venous thrombosis. Lancet 1977;ii:370-3.

(Accepted 18 fune 1980)

\title{
Nephrotic syndrome with slight proliferative changes in the glomeruli: response to prednisone
}

\author{
H RASHID, S EZEDUM, A R MORLEY, D N S KERR
}

\section{Summary and conclusions}

Seven patients with slight but definite proliferative changes in the glomeruli achieved complete remission of the nephrotic syndrome when treated with prednisone. The patterns of response and, in three cases, repeated relapse and response suggested that this was more than a coincidental spontaneous cure.

A controlled trial of corticosteroids in patients with slight proliferative glomerulonephritis and severe nephrotic syndrome should be carried out to verify these results.

\section{Introduction}

The value of corticosteroids in the childhood nephrotic syndrome was established without the need for a controlled trial. Patients with minimal lesion (the great majority) responded rapidly, reproducibly, and almost without exception. ${ }^{1}$ The value of corticosteroids in adults was less certain, ${ }^{12}$ so in 1963 the MRC set up a multicentre, controlled trial of prednisone in adult nephrotic syndrome. ${ }^{3}$ This gave clear-cut results that have been accepted almost everywhere in Britain. Adults with minimal lesion responded to steroids, while those with membranous and proliferative change did not. Prednisone had a significant penalty in morbidity and mortality.

The trial made an important contribution in its time but had

\footnotetext{
Departments of Medicine and Pathology, University of Newcastle upon Tyne, Newcastle upon Tyne NE1 4LP

H RASHID, MB, FCPS, research fellow

S EZEDUM, MB, MRCP, research fellow (present address: Renal Unit, University of Nigeria Teaching Hospital, Enugu, Eastern Nigeria) A R MORLEY, MD, MRCPATH, consultant pathologist D N S KERR, MSC, FRCP, professor of medicine
}

certain limitations. These are particularly apparent to us, since $20 \%$ of the patients were cared for in Newcastle and this was the only centre where the planned repeat biopsies were consistently performed. The initial specimens were examined by only light microscopy, and in $18 \%$ of cases the panel of pathologists arrived at different diagnoses. Most of these "doubtful" cases, on the borderline between minimal lesion and membranous or proliferative nephritis, were eventually included in the "minimal" group. Retrospective analysis of our cases shows clearly that some early examples of membranous glomerulonephropathy were included in this group, and the report indicates that the same was probably true of slight proliferative lesions. This may account for the slow response to steroids in $25 \%$ of the patients in the "minimal" group. Since all the prednisonetreated patients in this group who survived to 24 months became "protein free," however, the possibility arises that some patients who are now diagnosed as having membranous or proliferative glomerulonephritis are denied the benefits of steroid treatment unnecessarily. We report here on seven patients who, we believe, fall into this group. All had slight but definite proliferative lesions yet went into complete remission while receiving corticosteroids.

\section{Methods}

Selection of cases-After the MRC study ended we stopped using corticosteroids for proliferative glomerulonephritis in general and conducted no further controlled trials. We continued, however, to give prednisone to a few carefully selected patients with incapacitating nephrotic syndrome whose biopsy changes were sufficiently slight that they might have fallen into the "doubtful" category in the MRC trial. We report here on seven of these patients, who went into complete remission while receiving steroids. None had any evidence of systemic diseases that respond to steroids (systemic lupus erythematosus, polyarteritis nodosa, Wegener's granulomatosis, etc) or of the forms of proliferative nephritis that often remit spontaneously or on treatment of the primary cause (acute post-streptococcal nephritis, nephritis of subacute bacterial endocarditis, shunt nephritis). 